\title{
Uma análise das seleções da copa utilizando uma rede de transferências de jogadores entre países
}

\author{
Lucas G. S. Félix ${ }^{1}$, Carlos M. Barbosa ${ }^{1}$, Iago A. Carvalho ${ }^{2}$, \\ Vinícius da F. Vieira ${ }^{1}$, Carolina Ribeiro Xavier $^{1}$ \\ ${ }^{1}$ Departamento de Ciência da Computação - Universidade Federal de São João del-Rei \\ Av. Visconde do Rio Preto S/N - Colônia do Bengo \\ ${ }^{2}$ Departamento de Ciência da Computação - Universidade Federal de Minas Gerais \\ \{lucasgsfelix, cmagnobarbosa\}@gmail.com, iagoac@dcc.ufmg.br \\ \{carolinaxavier, vinicius\}@ufsj.edu.br
}

\begin{abstract}
Football is the most popular sport in the world. The growth in the number of transactions of purchase and sale, marketing, sponsorships, sale of tickets, TV contracts, among other forms of monetization of football makes the flow of values increasingly higher. The majority of works related to this sport is associated with sociological analysis. This work proposes a study focused on the transactions occurred among the football teams classified to the World Cup 2018 using complex networks techniques for an analysis of the transfer of players among these countries.
\end{abstract}

Resumo. O futebol é hoje o esporte mais popular do mundo. O crescimento no número de transações de compra e venda, marketing, patrocínios, venda de ingressos, contratos de TV, entre outras formas de monetização do futebol faz com que o fluxo de valores seja cada vez maior. Grande parte dos trabalhos relacionados a esse esporte são associados a análises sociológicas. Neste trabalho, é proposto um estudo focado nas transações feitas entre as seleções classificadas para a Copa do Mundo 2018 utilizando técnicas de redes complexas para uma análise da transferência de jogadores entre esses países.

\section{Introdução}

O futebol é hoje o esporte mais popular do mundo [Liebig et al. 2012, Palacios-Huerta 2004]. Devido a sua grande popularidade, gera um enorme fluxo financeiro. Somente na Europa, o futebol movimentou aproximadamente 25 bilhões de euros na temporada 2016/2017 [Deloitte 2016].

Um time de futebol possui diversas formas de compensação financeira inclusive: vendas de camisas, patrocinadores, cotas pagas por canais de TV, além de uma grande movimentação de valores através de transações de jogadores. Um clube pode comprar um jogador permanentemente ou então adquirir seus direitos temporariamente, através de empréstimo. Ambos modelos de transação envolvem uma compensação financeira [Liu XF 2016].

A Copa do Mundo FIFA é um evento esportivo que ocorre de 4 em 4 anos. Criado em 1928, teve sua primeira edição realizada em 1930 e, desde então, foram realizadas 20 edições. A vigésima primeira edição da copa do mundo será realizada na Rússia em 2018. 
O objetivo deste trabalho é estudar as propriedades da rede de transferências de jogadores de futebol entre os países participantes da Copa do Mundo de 2018 a fim de extrair informações para entender a dinâmica dessas transferências. Para isso, além das características básicas da rede, serão utilizados algoritmos de ranking e de detecção de comunidades em redes complexas.

Existem diversos estudos que abordam o futebol como tema principal, entretanto, apesar da importância e do tamanho do mercado de transferências de jogadores, existem poucos estudos sobre o mesmo, sendo que grande parte aborda somente o lado sociológico das transferências de jogadores, usando o futebol para ilustrar o movimento internacional de forças de trabalho [Maguire 1994, Maguire and Pearton 2000, Poli 2010, Roderick 2013].

No trabalho [Poli 2010], o autor mostra a globalização através das transações feitas no mercado do futebol. Nos trabalhos [Maguire and Pearton 2000, Maguire 1994], são feitas análises do impacto da migração no esporte, sendo o primeiro mais focado no desenvolvimento de jogadores europeus e o segundo na análise do fluxo de mão de obra não apenas no futebol, mas em todos esportes.

Em [Roderick 2013], os autores analisam o movimento de jogadores de futebol dentro de um mercado interno, entretanto, este é um trabalho qualitativo, onde não houve uma coleta de dados em quantidade, apenas uma entrevista feita com cerca de 49 jogadores. O trabalho de [Palacios-Huerta 2004] estuda o futebol através de análises estatísticas comportamentais temporais, investigando apenas ligas inglesas e dando uma visão econômica ao esporte. No artigo [Frick ], é analisado o mercado de transferências de atletas na Europa dando um foco mais empírico ao assunto, avaliando aspectos não considerados em nossas análises como salário de jogadores e tempo de carreira de jogadores.

Um trabalho anterior que modelou uma rede de transferências de jogadores e a estudou foi [Liu XF 2016], apontando algumas propriedades da rede construída com o objetivo principal de analisar o sucesso de um time através de suas transferências.

\section{Coleta e modelagem da rede}

Para obtenção da rede de transferências, foi utilizado como base o transfermarkt[tra ]. O transfermarkt é uma página na internet que possui uma grande base de dados, com diversas informações relacionadas ao futebol, como: estatísticas de resultados, tabelas de campeonatos e o principal objeto de estudo deste trabalho, os dados relacionados a transferências de jogadores. Para a coleta de dados, foram consideradas as transferências entre 1990 e 2017. Os dados relativos a anos anteriores ao ano de 1990 se mostraram pouco relevantes para o estudo, já que, além de estarem em pouca quantidade, os valores das transações se mostraram irrisórios quando comparado a valores dos anos seguintes.

Após a obtenção das páginas no formato $\mathrm{html}$, foi montado um parser responsável por fazer um pré-processamento das páginas e permitir a estruturação dos dados para extração das informações. Após formatação padrão, foi montado um banco de dados para facilitar eventuais consultas, que poderia auxiliar também em diversas análises, principalmente para modelagem de diversas redes de interesse para análises específicas.

As redes foram modeladas da seguinte forma: cada país foi considerado um 
vértice, e caso um país tenha realizado uma transferência para o outro país, uma aresta direcionada do país vendedor para o país comprador será adicionada, considerando como o peso das arestas a quantidade de transações feitas entre os países, levando em conta a direção.

\section{Análise da rede}

\subsection{Propriedades da Rede de Transferências}

A base de dados coletada possui transferências dos anos de 1990 a 2017, que totalizam aproximadamente 27 mil transferências nas quais estão 135 vértices, representando os países presentes na base e 597 arestas representando a conexão entre esses países quando houve transferência de jogadores entre eles. Contudo, como o estudo abrange apenas os países presentes na Copa do Mundo FIFA 2018, a rede foi reduzida para 32 vértices e 430 arestas, abrangendo um total de 13797 transações, o que representa um pouco mais 50\% do total de transferências da base, mostrando que os poucos países participantes da copa, representam grande parte das transações mundiais.

Conforme mostram os dados da Tabela 3.1, a densidade da rede é 0,40, o diâmetro é 4 e o coeficiente de clusterização é 0,70 , o que mostra que há uma grande movimentação de jogadores entre os países participantes da copa, e que essas transações, geralmente são recíprocas, já que a reciprocidade da rede é maior do que $70 \%$.

Verifica-se que a rede é disassortativa, o que significa que os países que negociam com muitos países tendem a negociar com países que negociam com poucos países, apontando para um desbalanceamento entre os investimentos dos países em seus campeonatos internos com jogadores estrangeiros.

\begin{tabular}{r|r} 
Propriedade & Valor \\
\hline Densidade & 0.40 \\
Diâmetro & 4 \\
Coeficiente de clusterização & 0.70 \\
Reciprocidade & 0.71 \\
Assortatividade grau & -0.22 \\
Grau máximo & 46 \\
Força máxima de saída & 521 \\
Força máxima de entrada & 1034
\end{tabular}

\section{Tabela 1. Propriedades da rede de países da Copa}

O grau máximo da rede é 46, valor que está associado a dois países muito importantes no futebol mundial: França e Alemanha. Esse valor indica que esses países são os que possuem o maior número de parceiros para compra e venda de jogadores. A força máxima de saída é 521, referindo-se ao total de vendas internacionais na rede de um país, o Brasil. Ou seja, o Brasil é o país que mais forneceu jogadores para os clubes dos países que estão na Copa. Por outro lado, o país que mais comprou jogadores de outros países foi a Inglaterra, que possui a força máxima de entrada da rede, 1034 arestas. As Figuras 1 e 2 mostram as distribuições de grau de entrada e de saída da rede. Essas curvas mostram que a rede possui muitos vértices de grau alto, logo, é possível perceber que os países da copa são, de fato, bastante representativos no cenário do futebol mundial. 


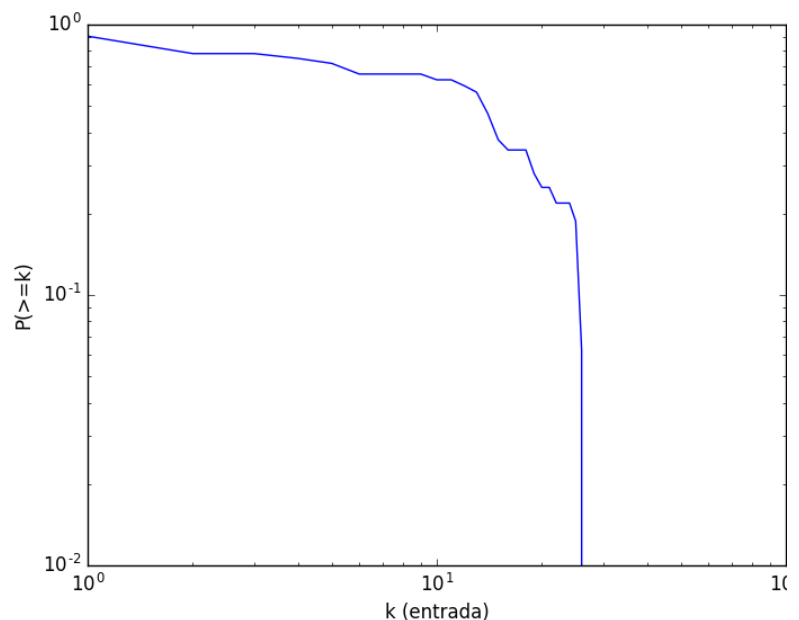

Figura 1. Distribuição de grau de entrada

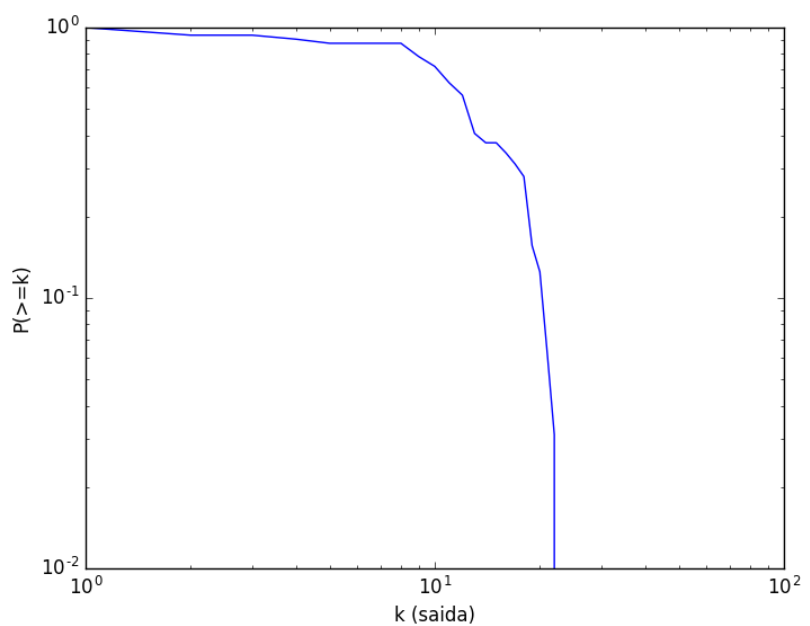

Figura 2. Distribuição de grau de saída

\subsection{Análise de centralidade}

Aplicando alguns algoritmos de centralidade de vértices, pode-se identificar os principais vértices da rede. Para isso foram consideradas três diferentes medidas de centralidade: Closeness [Freeman 1978], Betweenness [Newman and Girvan 2004] e PageRank [Page et al. 1999].

A centralidade de Closeness calcula o menor caminho entre um vértice e todos outros vértices do grafo, assim o vértice mais central é o que é mais próximo, em média, de todos os outros vértices.

A centralidade de Betweenness também é baseado em caminhos mínimos, contudo, este medida leva em consideração o número de caminhos mínimos que passam por um vértice. $\mathrm{O}$ vértice que é utilizado mais vezes como passagem nos caminhos mínimos será o vértice mais bem ordenado segundo esta medida.

Para aplicar medidas de Closeness e Betweenness, foi preciso inverter os valores dos pesos das arestas pois, como essas medidas utilizam como base os caminhos mínimos, a importância de um país, ligada ao número de transferências que ele faz, é mais apropriadamente representando os pesos de maneira inversa do original. Desta forma, para a aplicação dessas medidas, o peso das arestas foi calculado da seguinte forma: PesoAresta $=\sum 1 /\left(\right.$ QuantidadeTransacoes $\left.s_{a}^{b}\right)$.

A medida de PageRank, por outro lado, considera que um vértice é importante se ele é apontado por outros vértices importantes. O PageRank leva em conta o número e a qualidade das ligações de um vértice para determinar o quão importante ele é, portanto o peso da aresta foi a quantidade de transações.

Após o cálculo das medidas de centralidade para a rede, foram obtidos três listas ordenadas distintas, das quais a Tabela 2 apresenta as 10 primeiras posições.

Como é possível observar a partir da Tabela 2, há uma grande consistência entre as medidades de centralidade consideradas e os rankings obtidos apresentam poucas variações. Cinco países aparecem entre as 10 primeiras posições nas três listas, e estão 


\begin{tabular}{r|r|r|r} 
Posição & Closeness & Betweenness & PageRank \\
\hline 1 & Inglaterra & Inglaterra & Inglaterra \\
2 & Alemanha & Espanha & Alemanha \\
3 & Espanha & Alemanha & Espanha \\
4 & França & Brasil & Rússia \\
5 & Suíça & França & França \\
6 & Rússia & Argentina & Brasil \\
7 & Bélgica & Portugal & Bélgica \\
8 & Argentina & Costa Rica & Portugal \\
9 & Brasil & Dinamarca & Polônia \\
10 & Dinamarca & Egito & México
\end{tabular}

Tabela 2. Top-10 países ordenados por cada uma das medidas de centralidade.

em negrito na Tabela 2, assim como na Tabela 3. As maiores surpresas ocorreram na lista ordenada pela medida Betweenness, mostrando Egito e Costa Rica, que são grandes parceiros da Inglaterra.

A Tabela 3 mostra a quantidade de transações realizadas pelos 10 países que mais realizaram transações internacionais dentro da rede. Percebe-se que todos países presentes nesta tabela também estão presentes em pelo menos um dos rankings apresentados pela Tabela 2, desta forma podemos considerar que a importância dos países na rede está diretamente ligada ao número de transações internacionais realizadas.

\begin{tabular}{r|r|r} 
Posição & País & \# de transações \\
\hline 1 & Inglaterra & 1384 \\
2 & Alemanha & 1230 \\
3 & Espanha & 1096 \\
4 & França & 925 \\
5 & Brasil & 719 \\
6 & Portugal & 691 \\
7 & Argentina & 513 \\
8 & Rússia & 453 \\
9 & Bélgica & 416 \\
10 & Suíça & 337
\end{tabular}

Tabela 3. Quantidade de transações por país

\subsection{Análise de comunidades}

Uma investigação sobre a estrutura de comunidades na rede de transferências foi realizado com o objetivo de identificar grupos coesos de países dentro da rede e, para isso, utilizou-se alguns dos algoritmos para detecção de comunidades mais adotados na literatura. Apesar de se tratar de um mercado abrangente, onde qualquer país pode realizar o intercâmbio de jogadores com qualquer outro país, alguns "padrões de consumo"podem ser observados, como o fato de grandes países procurarem talentos estrangeiros para seus times locais em um mesmo grupo de países com mais frequência.

Os métodos para detecção de comunidades considerados neste trabalho foram: Multilevel [Blondel et al. 2008], Eigenvector [Newman 2006] e Fastgre- 
edy [Clauset et al. 2004], todos eles baseados na otimização da modularidade [Newman and Girvan 2004], a medida mais utilizada na literatura para avaliação da qualidade da partição de uma rede. A Tabela 4 mostra os resultados encontrados por cada um dos métodos, em termos do valor de modularidade e do número de comunidades.

\begin{tabular}{l|l|l} 
Algoritmo & Modularidade & \# de comunidades \\
\hline Eigenvector & 0.53 & 8 \\
Fastgreedy & 0.14 & 7 \\
Multilevel & 0.54 & 6
\end{tabular}

\section{Tabela 4. Comparação entre algoritmos de comunidade}

Considerando que os métodos para identificação de comunidades visam otimizar a modularidade como uma medida a ser maximizada, a análise da Tabela 4 permite identificar que o método multilevel oferece uma partição de melhor modularidade entre os métodos analisados e, por isso, essa partição foi escolhida para as análises seguintes.

Como apresentado na Tabela 4, o método multilevel identificou 7 comunidades, descritas na Tabela 5.

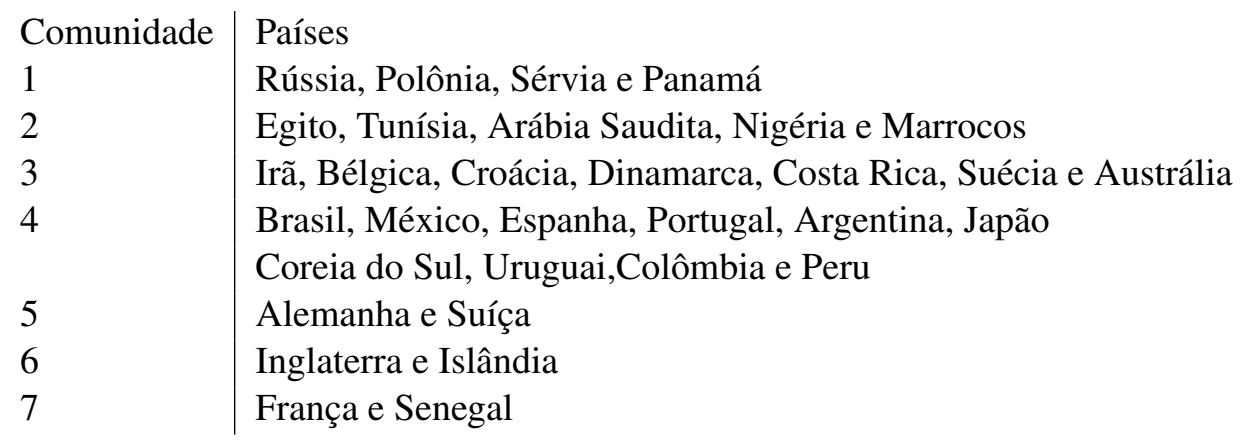

Tabela 5. Comunidades formadas

A Figura3 apresenta uma representação gráfica da rede de transferências com as comunidades identificadas através de cores.

A comunidade 1, formada por Rússia (país anfitrião dessa copa do mundo), Polônia, Sérvia e Panamá, possui apenas um entre os países com maior número de transferências registradas na base (Tabela 3), sendo este a Rússia, com 882 transações. Polônia e Sérvia possuem 428 e 308 transferências respectivamente. Já o Panamá, possui apenas duas transações registradas com outros países participantes da copa, sendo uma com a Polônia, o que ajuda a explicar o porquê da presença do Panamá neste grupo.

Para auxiliar na análise dos dados e ilustrar o montante movimentado por um país, foi considerada a balança comercial do mesmo. Essa balança mostra o quanto um país ganhou ou perdeu com a compra e venda de atletas. Para o cálculo da balança comercial foi considerada a soma de todas vendas subtraída da soma de compras. Os países com balança comercial negativa podem ser considerados como mercado consumidor de atletas. Já os países com balança comercial positiva podem ser considerados países fazenda, que são países que se caracterizam pela venda de jogadores e são frequentemente procurados para a compra de jogadores jovens que se destacaram em campeonatos nacionais, 


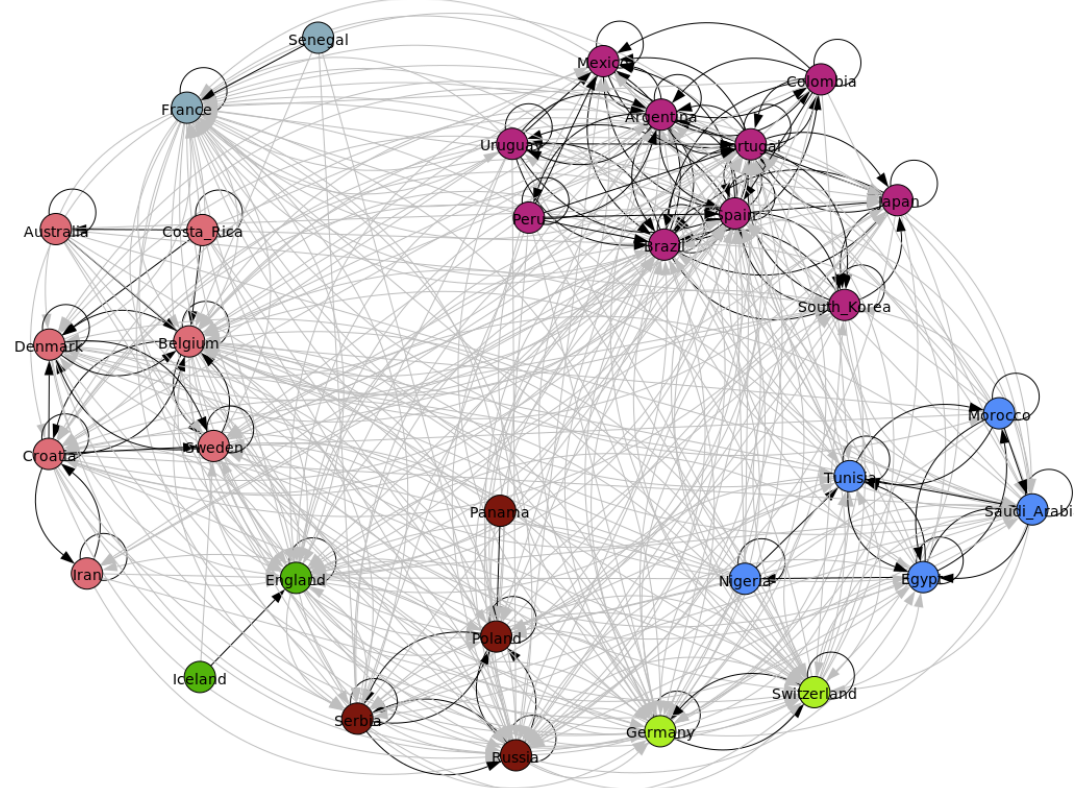

Figura 3. Rede de transferências de jogadores de futebol entre países da copa do mundo dividida em comunidades

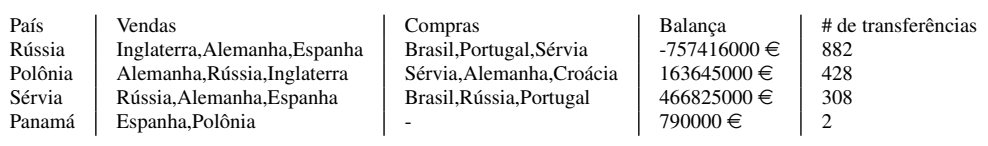

Tabela 6. Dados sobre os países presentes na comunidade 1

regionais e às vezes até nos campeonatos juniores. O cálculo da balança comercial é da forma: BalancaComercial $=\sum$ Vendas $-\sum$ Compras.

A Tabela 6 analisa os países presentes na comunidade 1, apresentando os países que mais compram de cada país de referência, os países que mais vendem para aquele país, a balança comercial e a quantidade de transferências realizadas por aquele país.

A análise dos países com os quais os integrantes da comunidade 1 realizam transferências com maior frequência, permite observar o motivo da ligação entre os mesmos. De acordo com a balança comercial do país, é possível ver qual sua posição com relação aos outros países, se é um país consumidor ou um país fornecedor de atletas.

É possível perceber que, nessa comunidade, todos os países estão conectados pelos seus compradores e fornecedores, sendo a Rússia o principal país da comunidade, por possuir a maior quantidade de transações e estar entre os principais parceiros comerciais de cada um dos países, com exceção do Panamá. Desta forma observa-se que a movimentação financeira dos três primeiros países é consideravelmente grande, sendo a Rússia, o único país presente na comunidade com a balança comercial negativa, um país consumidor, que possui clubes ricos que buscam atletas em outros países, enquanto os outros países Polônia e Sérvia são países produtores de talentos por possuírem uma balança comercial positiva.

A comunidade 2 é formada por Egito, Tunísia, Arábia Saudita, Nigéria e Marrocos, sendo que apenas a Arábia Saudita não pertence ao continente africano. Nesta comu- 
nidade, como pode-se observar na Tabela 7, os países não possuem uma grande quantidade de transferências e nenhum dos países presentes nessa comunidade se equipara, em número de transações realizadas, com grandes países da Europa e América. Além disso, assim como na comunidade 1, a maioria dos países possui a balança comercial positiva. Provavelmente esses países trocam frequentemente de jogadores entre si devido a proximidade geográfica deles, e essas transações foram suficientes para considerá-los como integrantes de uma comunidade.

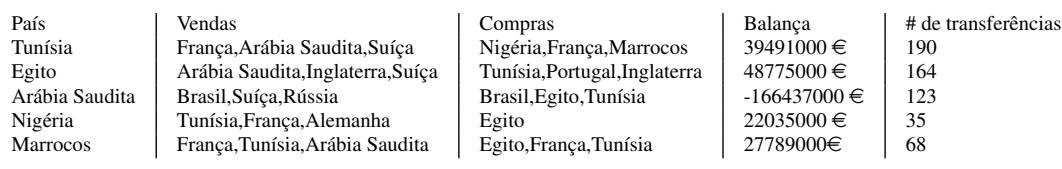

Tabela 7. Dados sobre os países presentes na comunidade 2

A comunidade 3, formada por Irã, Bélgica, Croácia, Dinamarca, Costa Rica, Suécia e Austrália é a comunidade com maior diversidade de continentes, tendo países pertencentes a Europa, América, Ásia e Oceania. Essa comunidade é caracterizada por possuir somente países com uma balança comercial totalmente positiva, como pode ser observado de maneira detalhada pela Tabela 8 .

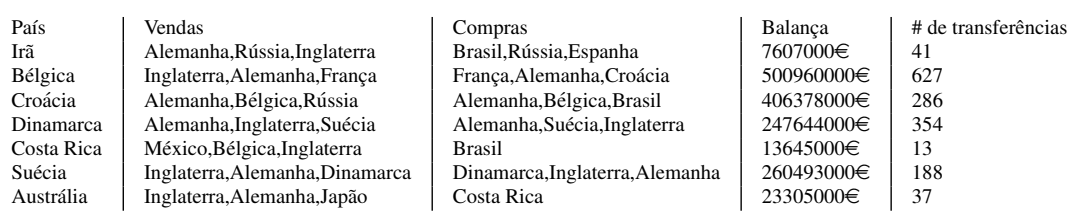

Tabela 8. Dados sobre os países presentes na comunidade 3

A Tabela 8 mostra que os países europeus possuem uma quantidade maior de transações e, consequentemente, um maior valor na balança comercial. Estes países funcionam como um trampolim para futura venda de jogadores para outros países europeus, envolvendo times de maior prestígio.

Das poucas transações presentes na Oceania a maioria são transações de venda. $O$ continente possui 62 transações de venda e 7 transações de compra registradas, fazendo desse continente o que possui menor quantidade de transações nesta comunidade.

Na Tabela 9, a distribuição de transações por continente é apresentada.

\begin{tabular}{l|l|l|l} 
Continente & \# compras & \# vendas & \# internas \\
Asia & 834 & 281 & 539 \\
América & 435 & 1853 & 1296 \\
Africa & 60 & 388 & 384 \\
Europa & 2222 & 966 & 21057 \\
Oceania & 7 & 62 & 4
\end{tabular}

Tabela 9. Quantidade de transações de cada continente

A comunidade 4 é a maior comunidade presente na rede, com um total de 10 países. Essa comunidade é caracterizada pela presença de países de diversos continentes 


\begin{tabular}{l|l} 
Continente & Valor médio vendas \\
Asia & $1.535 .288 €$ \\
América & $2.894 .209 €$ \\
Africa & $604.533 €$ \\
Europa & $2.202 .635 €$ \\
Oceania & $415.322 €$
\end{tabular}

Tabela 11. Valor médio pago em transações por continente

como Brasil, México, Argentina, Uruguai, Colômbia e Peru, representando a América, Japão e Coreia do Sul representando Ásia e, ainda, Espanha e Portugal representando a Europa.

A Tabela 10 apresenta os dados dos países presentes na comunidade 4. Nesta comunidade, está presente uma maior quantidade de países vencedores de copas do mundo, sendo eles Brasil, Argentina, Espanha e Uruguai.

\begin{tabular}{l|l|l|l|l} 
País & Vendas & Compras & Balança comercial & \# de transferências \\
Espanha & Inglaterra,Alemanha,Portugal & Argentina,Inglaterra,Portugal & $-906437000 €$ & 1704 \\
Portugal & Espanha,Inglaterra,França & Brasil,Espanha,Argentina & $1468658000 €$ & 871 \\
Brasil & Alemanha,Portugal,Espanha & Argentina,Portugal,Espanha & $2257058000 €$ & 1133 \\
Argentina & Espanha,México,Brasil & Espanha,Uruguai,México & $1491868000 €$ & 794 \\
México & Argentina,Brasil,Espanha & Argentina,Brasil,Colômbia & $-72455000 €$ & 298 \\
Japão & Alemanha,Brasil,Inglaterra & Brasil,Alemanha,Coreia do Sul & $42627000 €$ & 144 \\
Uruguai & Espanha,Argentina,Portugal & Brasil,Argentina,Espanha & $328424000 €$ & 122 \\
Colômbia & Argentina,Brasil,México & México,Argentina,Brasil & $188658000 €$ & 89 \\
Peru & Alemanha,México,Portugal & Argentina & $22703000 €$ & 27 \\
Coreia do Sul & Alemanha,Japão,Inglaterra & Brasil,Sérvia,Croácia & $58499000 €$ & 73
\end{tabular}

Tabela 10. Dados sobre os países presentes na comunidade 4

Assim como na comunidade 1, apenas uma pequena parte da comunidade possui uma balança comercial negativa, sendo estes Espanha e México.

Como esta comunidade possui um número bem grande países, optou-se por analisar a mesma por continente. Primeiramente, analisando os países da América, que são maioria nessa comunidade, observa-se que o Brasil possui o maior número de transações e o Peru o menor número de transações. Através dessa comunidade é possível visualizar um padrão que é compartilhado pela maioria dos países da América do Sul e América Central que é a balança comercial positiva, demonstrando a falta de poder de compra dos clubes pertencentes a esses países para trazer atletas de outros continentes ou mesmo manter atletas de origem nacional de qualidade dentro do próprio país.

A América hoje possui a maior média de venda de jogadores entre todos os continentes, como podemos ver na Tabela 11, sendo que considerando apenas transações externas de compra e venda, cerca de $81 \%$ das transações deste continente são transações de venda. Desta forma a Tabela 11 corrobora que este é um mercado produtor de talentos para clubes de outros países com poder aquisitivo maior.

Analisando os países asiáticos presentes na comunidade, tendo Japão e Coreia do Sul como representantes nesta comunidade, observa-se que ambos possuem uma balança comercial positiva, o que não representa o padrão de consumo asiático como um todo, pois a maioria das movimentações de compra superam as de venda. Esse padrão é alavancado pela China, que lidera como país com maior transações gerais dentro da Ásia movimentando grandes quantidade financeiras com grandes contratações de jogadores 
estrangeiros [the ]. A China, entretanto, mesmo sendo um país com fluxo considerável no mercado de transação de atletas não está presente entre os países classificados para copa de 2018, o que aponta que não são apenas investimentos em jogadores estrangeiros para fortalecimento das competições nacionais que influenciam no desempenho da seleção para classificação e participação em uma copa do mundo.

Os países do continente europeu nesta comunidade são Espanha e Portugal. Neste grupo fica claro o domínio de alguns países pertencentes a esse continente no mercado de transações. Cada um dos países presentes nesta comunidade funciona como um agente diferente na rede estudada e no mercado como um todo. A Espanha é um país comprador de talentos para fortalecimento do campeonato nacional, de forma que os clubes pertencentes a esses países adquirem tais atletas sem pensar em uma eventual venda do jogador. Portanto, a Espanha possui uma balança negativa, abrigando alguns dos clubes mais ricos do mundo [ric ], que dispõem de montantes significativos para manter os atletas dentro de seu domínio e sempre comprar novos reforços para manutenção dos clubes.

Já Portugal tem servido como vitrine para os atletas, que passam pelos clubes portugueses para ter maior visibilidade no mercado europeu ao atuar neste país, servindo como um mercado impulsionador de atleta, aumentando atributos e o valores dos jogadores. Geralmente, times portugueses compram jogadores com o objetivo da venda por um preço maior que o comprado, obtendo assim um lucro na venda do jogador fazendo, assim, que Portugal possua uma balança comercial positiva.

Hoje a Europa é o centro do futebol mundial, onde há as principais ligas, com os melhores jogadores do mundo [fif ]. Grande parte dos países europeus com balança comercial positiva funcionam como país trampolim para uma posterior venda desses jogadores. Entretanto, isso não ocorre com todos os países, já que com a consolidação de campeonatos mais fortes devido a compra de jogadores de maior habilidade faz com que o nível dessas competições aumente, fazendo com que haja uma evolução dos jogadores e dos preços de venda do atleta. Para uma melhor visualização disso, foi analisada a média de compra e venda nesses países.

\begin{tabular}{l|l|l} 
País & Vendas & Compras \\
Rússia & $1.681 .381 €$ & $1.830 .670 €$ \\
Polônia & $693.962 €$ & $268.694 €$ \\
Sérvia & $972.090 €$ & $408.254 €$ \\
Espanha & $3.128 .515 €$ & $2.907 .998 €$ \\
Portugal & $2.089 .052 €$ & $1.975 .059 €$ \\
Bélgica & $1.738 .789 €$ & $1.022 .196 €$ \\
Croácia & $1.090 .413 €$ & $646.089 €$ \\
Dinamarca & $1.503 .512 €$ & $943.660 €$ \\
Suécia & $1.124 .419 €$ & $418.479 €$ \\
Alemanha & $1.529 .849 €$ & $1407114 €$ \\
Suíça & $1.337 .964 €$ & $908.760 €$ \\
Inglaterra & $2.886 .619 €$ & $3.013 .590 €$ \\
França & $2.098 .838 €$ & $2.145 .160 €$ \\
Islândia & $278.750 €$ & $0 €$
\end{tabular}

Tabela 12. Tabela mostra o valor médio pago em transações por continente 
Pode-se ver na Tabela 12 a média de compra e vendas dos países pertencentes a Europa que estão presentes na copa do mundo 2018. De forma parcial pode-se ver países que compram jogadores por uma média mais baixa e vende a um preço mais alto. Se associarmos essa informação a dados de balança comercial e aos países ao qual esse país se associa para fazer compras, podemos definir se esse é um país consumidor ou fornecedor.

\section{Conclusão}

Este trabalho apresentou a análise de uma rede de transferências de jogadores de futebol entre países participantes da copa do mundo. Foram utilizadas técnicas de redes complexas como ranking por algumas medidas de centralidade e detecção de comunidades.

Observou-se que esses países são bastante representativos no futebol, abrangendo $50 \%$ das transferências mundiais as quais são bastante frequentes entre a maioria dos países da rede. Pode-se perceber alguns destaques de papéis de alguns países empregam no futebol mundial, por exemplo, se comparamos o Brasil, um país fazenda com a Inglaterra, um país de ligas ricas, pode-se ver dois países bastante diferentes em termos humanos e econômicos. A Inglaterra possui o $16^{\circ} \mathrm{IDH}$ do mundo, uma expectativa de vida de 80,8 anos e seus cidadãos estudam em média por 16, 3 anos. Enquanto o Brasil é o $79^{\circ}$ de acordo com o IDH, tem expectativa de vida de 74,7 e seus cidadãos estudam em média 15,2. A Inglaterra importa mais matéria prima e exporta produtos industrializados e medicamentos, enquanto o Brasil exporta matéria prima e produtos agrícola e importa produtos industrializados. No Brasil o futebol ainda é uma grande esperança de muitos jovens para mudança de realidade de vida.

As listas top-10 geradas pelas diferentes medidas de centralidade mostraram que os países de ligas ricas são os países mais centrais da rede para qualquer medida de centralidade observada, apesar de países fazenda e países que tem tradição de comprar jogadores para valorização e futura venda e lucro também são encontrados nas listas.

Considerando a estrutura de comunidades, observa-se que os maiores parceiros comerciais estão unidos nos mesmos grupos. No entanto, os países mais centrais estão separados em comunidades isoladas com um parceiro eventual, possivelmente devido ao fato de estes países menores possuírem poucas transações com os demais países da rede.

Como trabalhos futuros, pretende-se realizar análises de comunidades com métodos que consigam identificar comunidades com sobreposição, pois acredita-se que este tipo de abordagem pode trazer mais informações interessantes. Pretende-se ainda utilizar uma rede com o montante financeiro como peso das arestas para comparação de resultados, além de analisar as redes separadas pelos anos que antecederam a copa e confrontar os resultados com o desempenho das seleções naquele período.

\section{Agradecimentos}

Os autores agradecem às agências de fomento: Capes, CNPq e FAPEMIG.

\section{Referências}

fifa-11. http://www.fifa.com/the-best-fifa-football-awards/fifa-fifpro-world11/index.html. Accessed: 2017-12-04. 
Richest clubs. http://uk.businessinsider.com/the-20-richest-football-clubs-in-the-world2017-1. Accessed: 2018-01-13.

The Guardian. www.theguardian.com/football/these-football-times/2017/jan/05/chinachinese-super-league-oscar-carlos-tevezWhy Chinese clubs are breaking transfer records - and why players are wise to go. Accessed: 2017-11-20.

Transfermarkt. transfermarkt.com/statistik/transferrekorde. Accessed: 2017-11-17.

Blondel, V. D., Guillaume, J.-L., Lambiotte, R., and Lefebvre, E. (2008). Fast unfolding of communities in large networks. Journal of Statistical Mechanics: Theory and Experiment, 2008(10):P10008.

Clauset, A., Newman, M. E. J., and Moore, C. (2004). Finding community structure in very large networks. Phys. Rev. E, 70:066111.

Deloitte (June 2016). Annual review of football finance.

Freeman, L. C. (1978). Centrality in social networks conceptual clarification. Social Networks, page 215.

Frick, B. The football players' labor market: Empirical evidence from the major european leagues. Scottish Journal of Political Economy, 54(3):422-446.

Liebig, J., Rhein, A. V., Kastner, C., Apel, S., Dorre, J., and Lengauer, C. (2012). Largescale variability-aware type checking and dataflow analysis.

Liu XF, Liu Y-L, L. X.-H. W. Q.-X. W. T.-X. (2016). The anatomy of the global football player transfer network: Club functionalities versus network properties. PLoS ONE, 11(6).

Maguire, J. (1994). Preliminary observations on globalisation and the migration of sport labour. The Sociological Review, 42(3):452-480.

Maguire, J. and Pearton, R. (2000). The impact of elite labour migration on the identification, selection and development of european soccer players. Journal of Sports Sciences, 18(9):759-769. PMID: 11043901.

Newman, M. E. J. (2006). Finding community structure in networks using the eigenvectors of matrices. Phys. Rev. E, 74:036104.

Newman, M. E. J. and Girvan, M. (2004). Finding and evaluating community structure in networks. Phys. Rev. E, 69:026113.

Page, L., Brin, S., Motwani, R., and Winograd, T. (1999). The pagerank citation ranking: Bringing order to the web. Technical Report 1999-66, Stanford InfoLab. Previous number $=$ SIDL-WP-1999-0120.

Palacios-Huerta, I. (2004). Structural changes during a century of the world's most popular sport. Statistical Methods and Applications, 13(2):241-258.

Poli, R. (2010). Understanding globalization through football: The new international division of labour, migratory channels and transnational trade circuits. International Review for the Sociology of Sport, 45(4):491-506.

Roderick, M. (2013). Domestic moves: An exploration of intra-national labour mobility in the working lives of professional footballers. International Review for the Sociology of Sport, 48(4):387-404. 